\title{
LOS JEEES POLÍTICOS COMO INTERMEDIARIOS DEL NUEVO ORDEN SOCIAL
}

JESÚS GÓMEZ SERRANO

Departamento de Historia/UAA

Francisco Javier Delgado Aguilar, Jefaluras políticas. Dinámica política y control social en Aguascalientes 1867-1911, Aguascalientes, Universidad Autónoma de Aguascalientes/Gobierno del Estado de Aguascalientes, 2000, 325 pp.

Hay muchas maneras de contar la historia de los centros y departamentos que conforman nuestra Universidad Autónoma de Aguascalientes. Por regla general, se prefieren las versiones institucionales, que recuerdan efemérides consagradas, discursos grandilocuentes, informes, fundaciones y episodios que ante los ojos de sus actores tienen una relevancia de la que en el fondo tal vez carecen. Con frecuencia, una vez que el polvo levantado por las batallas de todos los días se ha asentado y se tiene un poco más de perspectiva, se advierte que el brillo de esos acontecimientos era sólo momentáneo y aparente.

Otra manera de contar esa misma historia es a través de las obras de los universitarios: la cátedra de un profesor que por convicción no falta nunca a clase, un libro que es el resultado de varios años de esfuerzo callado y sostenido, la tenacidad de un alumno que es capaz de vencer todos los obstáculos que se atraviesan en su camino. No sólo de los hombres, también de las instituciones puede decirse: "por sus obras los conoceréis". Y la principal obra o producto de la Universidad son sus alumnos, profesionistas el día menos pensado, ciudadanos activa y responsablemente incrustados en el acontecer social, jóvenes investigadores que nos sorprenden gratamente con libros como el de Francisco Javier Delga- 
do. Creo que esta otra forma de contar la historia de nuestra alma mater, aunque menos solemne y pretenciosa, puede resultar más veraz e instructiva.

En este sentido, no me parece una exageración decir que un egresado como Javier Delgado justifica la existencia del todavía joven Departamento de Historia. $\mathrm{Si}$, atento a sus muchos pecados y omisiones, Dios o alguno de sus vicarios decidieran un día aniquilar ese departamento y obligarnos a los profesores a encontrar un empleo más provechoso, tendrían que reparar en la existencia de Javier Delgado, un hijo legítimo de ese departamento, quien con sus libros, sus artículos y su excelente desempeño como profesor, podría tal vez contener la divina ira.

Buen alumno hasta hace un par de años, Javier decidió en forma precoz que su vocación se encontraba entre los libros y los archivos. Por eso, cuando terminó su licenciatura, supo o intuyó que en realidad apenas había iniciado su camino, un camino largo y difícil, en el que habrá de persistir hasta conquistar cumbres que por lo pronto apenas aparecen insinuadas en el lejano horizonte.

Sin embargo, a pesar de haberse embarcado en una empresa académi- ca de largo plazo, Javier tiene buen sentido de lo práctico. Lector infatigable, asiduo consultor de archivos en Aguascalientes y la ciudad de México, logró madurar en forma muy temprana aportaciones llenas de sustancia a la historiografía regional. En uno de los primeros números de Caleidoscopio apareció una reseña suya, que lo exhibió como un lector atento y sutilmente crítico, y un poco más adelante dos artículos, uno sobre las actividades de los subdelegados en Aguascalientes a fines del siglo XVIII, resultado de sus pesquisas en el Archivo General de la Nación, y otro que propone una novedosa y estimulante revisión crítica de la Historia del estado de Aguascalientes, de Agustín R. González.

\section{Sentido de SU APORTACIÓN}

Como es sabido, la historiografía regional ha conocido un desarrollo notable durante los últimos veinte años. En ese lapso, de hecho, se han publicado más libros y artículos especializados que todo lo conocido para los cien años anteriores, contados a partir de la publicación, en 1881, en la citada obra de Agustín R. González.

Este auge sorprendente de la investigación y la literatura históricas 
proporcionan al investigador una plataforma de la que hasta hace poco se carecía, pero al mismo tiempo supone una complicación, pues el que quiere sumarse al debate debe considerar con detenimiento las aportaciones precedentes. Hasta hace pocos años uno podía interesarse casi por cualquier tema con la seguridad de que lo suyo constituiría una aportación original, o la primera piedra de un edificio que otros se encargarían de seguir levantando. Hoy las cosas han cambiado, porque el campo de la historiografía regional está lleno de mojoneras, señales muy precisas que indican que alguien ha pasado por ahí, y es menester saber hasta donde han llegado.

Javier Delgado incursiona en el campo de la historia política con la clara conciencia de que otros lo han precedido. En su libro es evidente que él conoce esas aportaciones, que las ha estudiado y apreciado críticamente, que sabe con exactitud hasta dónde han llegado sus predecesores y que, por lo mismo, sabe también a partir de donde puede intentar una aportación original.

"No me parece que éste sea un asunto menor. Por un lado hay en el autor una plausible actitud de humildad, en el sentido filosófico del tér- mino; la sabiduría elemental pero difícil de quien reconoce que otros saben. Por el otro, este adecuado conocimiento del campo en el que incursiona le permite formular con precisión y en forma fecunda sus propios planteamientos. Como sabe hasta donde llegaron sus colegas, él propone un paso adelante en una dirección que con toda certeza puede identificar como correcta.

Específicamente, Javier Delgado ha evitado la tentación fácil de intentar una nueva crónica de los acontecimientos políticos que se registraron en Aguascalientes durante la segunda mitad del siglo Xıx. ¿Para qué? Otros lo han hecho antes y aunque él conoce muy bien los alcances y límites de esos libros, sabe que su incursión puede resultar más provechosa si propone el análisis de las instituciones, sobre todo las jefaturas políticas y los cabildos. Se trata de una vía de acceso al análisis histórico muy fecunda y sugerente, como lo acaba de demostrar el libro Las instituciones de gobierno y la élite local, dé Beatriz Rojas.

La elección de este tema, le permite al autor madurar una contribución original a la historia política de Aguascalientes. Usando como telón de fondo y referencia permanente las 
crónicas disponibles, propone un análisis minucioso, lleno de imaginación y fundado en documentación original, de las jefaturas políticas, una institución muy importante, a la que hasta ahora los historiadores no habíamos dedicado la debida atención.

Aunque no sea el propósito de su autor, este libro nos demuestra que en la historiografía regional, a pesar del vigoroso desarrollo que ha conocido durante los últimos veinte años, hay una enorme cantidad de temas interesantes e inéditos, a partir de los cuales se pueden hacer contribuciones críticas y originales. También nos muestra que el camino de estas nuevas aportaciones no supone la ignorancia, fingida o real, de lo que se ha hecho antes, ni mucho menos el desdén hacia los libros y artículos de los colegas. Todo lo contrario, pues parece haber una correlación directa entre el grado de conocimiento que se tenga de un campo específico del conocimiento y la calidad y originalidad de la aportación que se pretende hacer.

\section{EstruCtura DEL LIBRo}

El estudio de Javier Delgado realmente resulta novedoso y constituye una aportación original al estudio de nues- tro siglo XIX. El autor demuestra que los jefes políticos eran personajes muy importantes que tenían bajo su control a los ayuntamientos y que influían decisivamente en las elecciones, las cuales manipulaban a su antojo. Como dijo Laurens Perry, en la época de la República Restaurada, y tal vez también durante el Porfiriato, los jefes políticos fueron "los electores fundamentales", los verdaderos y tal vez únicos intérpretes de la mal llamada voluntad popular. Al concentrar su atención en estos personajes, Francisco Javier ha logrado enriquecer en forma sustancial el conocimiento que tenemos del desarrollo político regional. Tal vez algunos pensaban que ya todo estaba dicho, pero el autor de este libro, con información fresca y argumentos inteligentes, ha demostrado que en el campo de la investigación histórica lo que se agota no son los temas, sino la imaginación y la capacidad de los autores para decir algo nuevo e interesante. El libro está dividido en dos partes. En la primera, precedida por una introducción sobre el carácter de las jefaturas políticas y la forma en la que evolucionó esa institución a lo largo del siglo XIX, se propone un análisis de la historia política regional desde el momento en el que triunfó la Re- 
pública Restaurada, en diciembre de 1866, hasta las elecciones de 1887, que le permitieron a Francisco G. Hornedo reinstalarse en la gubernatura y afianzar en forma incontrastable su control del estado. Se trata de una etapa de la evolución histórica regional sobre la que otros autores nos hemos interesado, pero Javier Delgado se acerca a ella con una perspectiva diferente. Más que un seguimiento de los hechos principales, en buena medida ya conocidos, lo que propone es un análisis de la actuación de los principales actores políticos. Sin olvidar al gobernador, que concentra fuerza y recursos, se detiene en los jefes políticos, que fueron mucho más que funcionarios subalternos o dóciles correas de transmisión de órdenes superiores, y en los ayuntamientos, cuyo papel y protagonismo se reivindican. En el fecundo y lúcido análisis del papel jugado por estos actores radica uno de los más claros méritos del libro de Javier Delgado. El título del libro sugiere que el estudio está limitado al análisis de los jefes políticos, pero me parece que se le concede tanta o mayor importancia al estudio de los ayuntamientos, los que figuran a lo largo de todo el texto, unas veces defendiéndose de los embates de los jefes políticos, otras tratando de ampliar sus facultades legales y siempre reivindicando los fueros de una institución a la que algunos autores han identificado como piedra angular del desarrollo político del país.

En la segunda parte del libro se hace a un lado la crónica política para intentar el análisis de las relaciones que había entre las actividades del jefe político en materia de mantenimiento del orden y seguridad pública y el propósito superior de la élite gobernante y el Estado liberal de transformar en profundidad a la sociedad, una sociedad que se juzgaba arcaica y aferrada a principios corporativos que debían ser exterminados. El autor trata de demostrar que el jefe político fue "uno de los principales instrumentos utilizados por el Estado para crear ciudadanos con pautas de conducta homogéneas y apegadas a principios y valores de tipo burgués e individualista". (p. 164) Apoyado en algunos conceptos del filósofo Michel Foucault, se examinan las atribuciones legales que tenía el jefe político, subrayándose el hecho de que estos funcionarios eran uno de los principales agentes del orden público, pues contaban con facultades casi discrecionales para perseguir a los bandidos, combatir a toda 
clase de delincuentes, reprimir a la población e imponer castigos.

\section{Méritos del TRABajo}

Uno de los méritos del libro es que se acerca a los hechos sin prejuicios, analizándolos con la mayor objetividad posible. Eso le permite al autor mantener una sana distancia con los clisés de moda y proponer una imagen dinámica y convincente de la forma en que evolucionaron las jefaturas políticas. Demuestra, por ejemplo, que la Ley Orgánica para la División Territorial y Régimen Interior del Estado, promulgada en 1873, introdujo cambios de importancia, pues los jefes políticos dejaron de ser presidentes de los ayuntamientos y éstos contaron en lo sucesivo con mayores márgenes de autonomía, pues " ya no tendrían que sesionar forzosamente bajo la presidencia y la autoridad directa del jefe político". Los jefes políticos no desaparecieron ni dejaron de ser "una instancia de control político y administrativo y administrativo sobre los cuerpos municipales", pero su papel se redefinió. En una forma que puede parecer paradójica, pero ajustada a la verdad de los hechos, los jefes políticos perdieron la presidencia de los cabildos, pero con- servaron "la capacidad para ejercer un control constante y efectivo sobre sus actividades"(pp. 66-68). Un buen ejemplo de los excesos que un jefe político podía cometer en su relación con el ayuntamiento lo proporciona el legendario Pedro Torres, que sin inmutarse llegó a ofender de manera personal y directa al tesorero municipal, sin que fuera sancionado; enterado de sus faltas, el gobernador Francisco G. Hornedo no pareció alarmado, ni se creyó obligado a reprenderlo. En determinado momento, Hornedo prefirió enemistarse con el ayuntamiento y aceptar la renuncia de la mitad de sus miembros, antes que meter en cintura a Torres (pp. 111-114).

A todo lo largo del libro se defiende en forma exitosa la tesis según la cual los jefes políticos eran un excelente instrumento de control administrativo y político que los gobernadores, a pesar de sus rituales promesas de respeto a las leyes y a la autonomía municipal, utilizaron en forma amplia. En este sentido, no deja de ser curioso constatar que el gobernador Hornedo se limitó a hacer lo que habían hecho sus antecesores Ignacio T. Chávez y Rodrigo Rincón, a pesar de que él, como diputado de la oposición, había criticado muchas 
veces y en todos los tonos esos "abusos". Más allá de la retórica, en todos los gobernadores de la época de la República Restaurada y los primeros años del Porfiriato se observa, dice Javier Delgado, una clara aspiración al control de las autoridades municipales y "un reforzamiento del centralismo mediante el fortalecimiento del papel de los jefes políticos", que nunca perdieron su carácter de "funcionarios favoritos" del titular del ejecutivo estatal (p. 123).

En el último capítulo de la primera parte el autor hace una evaluación de conjunto interesante, en el sentido de que la estabilidad política que trajo consigo el Porfiriato, sobre todo a partir de la segunda presidencia de Díaz (1884-1888), se tradujo en una reorganización de las pugnas por el poder que tenían lugar en todas las regiones del país. Los ayuntamientos y los congresos locales perdieron fuerza y dejaron de ser agentes de la resolución de pugnas políticas; en su lugar, fueron cobrando fuerza los contactos personales, las redes de influencia y el clientelismo. El ascenso y la consolidación de un régimen caudillista, se tradujeron en la "desinstitucionalización" de la vida pública, la centralización del poder, el fortalecimiento de las jefaturas políticas y el auge del personalismo. Esta nueva manera de hacer política favoreció las tendencias centralistas y oligárquicas, sometió a los ayuntamientos a una situación de pupilaje legal y -dice el autor- "puso en el centro de las disputas a las jefaturas políticas, que vinieron a ocupar el lugar de los ayuntamientos como instrumentos de las facciones para asegurar su representatividad en la localidad" (p. 148). Por su parte, los cabildos perdieron muchas de sus antiguas facultades y dejaron de ser "la trinchera de la oposición", lo que en otras palabras quiere decir que se le allanó el camino a la centralización política y administrativa. (p. 157).

\section{Aprovechamiento Crítico \\ DE LA BIBLIOGRAFÍA}

Otro mérito del trabajo es la forma en la que se articula la consulta de los archivos y la aportación de datos y referencias no conocidos con el seguimiento crítico de la bibliografía que se ocupa de los temas que le interesan. En la crónica que se hace de la vida política local desde el arribo a la gubernatura del coronel Jesús Gómez Portugal, en diciembre de 1866, hasta el término de la gestión del tuxtepecano Francisco G. 
Hornedo, en 1880, no se pierde nunca de vista el relato de Agustín R. González, ni tampoco la versión más reciente que se ofrece en el primer tomo de la obra Aguascalientes en la historia. Ambos libros se utilizan en forma amplia, dando cada vez que es necesario la correspondiente cita al pie de página, pero gracias a su conocimiento de la prensa de la época y de los archivos, Javier Delgado ofrece unas veces datos nuevos y otras visiones de conjunto que enriquecen nuestro conocimiento de la época y sus personajes.

En este sentido, pienso que el libro constituye un buen ejemplo de la forma en la que puede y debe avanzar el conocimiento histórico regional: no a partir de un ilusorio vacío, que le da al autor la falsa sensación de estar diciendo las cosas por primera vez o de estar acercándose a temas que permanecían inéditos, sino a partir del aprovechamiento inteligente de lo que se ha hecho antes. Un aprovechamiento que no excluye el distanciamiento crítico, pues el análisis de la documentación y la consulta de la literatura más reciente le permiten al autor proponer un mejor entendimiento de los hechos. Al hablar de las elecciones para gobernador que ganó Rodrigo Rincón Gallar- do, por ejemplo, hace notar "que la oposición no fue tan insignificante como se ha hecho aparecer [en el libro de Jesús Gómez Serrano] y que era lo suficientemente fuerte como para adueñarse de una jefatura política y obtener mayoría en el congreso local, a pesar de las maniobras del gobierno" (p. 79). Y agrega algo que quienes nos interesamos por estos mismos temas antes que él habíamos ignorado: el gobernador Ignacio T. Chávez terminó en 1875 su gestión “acosado por una oposición que él mismo, con sus prácticas centralistas y monopolizadoras, había contribuido a crear", lo que viene a contradecir o "matizar", como dice con gentileza el autor, la visión que teníamos otros en el sentido de que Chávez había puesto su mejor esfuerzo en reunificar a la familia liberal. Me parece una observación no sólo pertinente, sino enriquecedora de nuestra comprensión de la época.

En el capítulo que dedica a la gestión del gobernador Rodrigo Rincón Gallardo, explora las circunstancias en las que creció la oposición y las razones por las cuales ésta se volvió porfirista. Con claridad, dice que se trata de un tema insuficientemente tratado en la literatura histórica, en la que sólo se había señalado la exis- 
tencia de cierto "ánimo favorable" a los insurrectos de Tuxtepec, sin que realmente se estudiaran los "factores políticos" que permitieron la formación y consolidación de esa fuerza ( $p$. 89). Pienso que este es un ejemplo más de aprovechamiento inteligente y crítico de los libros escritos por otros colegas. En contra de esa perniciosa costumbre que hace de cada historiador un "descubridor" de temas y documentos, Javier Delgado se asume como un eslabón de una cadena que iniciaron otros y a la que seguramente se agregarán más adelante las aportaciones de otros muchos historiadores. Al mismo tiempo, vence también la fácil tentación iconoclasta, ese afán muy frecuente en los jóvenes de destruir o derribar ídolos, trazando de esa manera forma fronteras insalvables en apariencia con las generaciones anteriores. En muchas páginas de su libro, Javier Delgado hubiera podido hacerlo, pero prefirió siempre la alusión respetuosa. Es crítico y bastante explícito cada vez que lo consideró necesario, pero con enorme gentileza y generosidad de espíritu evitó cualquier referencia o comentario que pudieran malinterpretarse.

En resumen, de muchas maneras el libro de Javier Delgado demuestra que para poner un nuevo peldaño en esa escalera ascendente que forma el conocimiento histórico es necesario pisar con firmeza los que otros han puesto con anterioridad, aunque algunos de esos escalones empiecen a resentir los efectos del tiempo y la polilla. Los saltos al vacío, aparte de cómicos, son suicidas.

\section{SALUdABLES PROVOCACIONES}

Por momentos, las aportaciones del autor tienen el carácter de provocaciones, pues no encajan con la idea romántica que se ha tenido siempre de algunos aspectos de la historia local. En el capítulo XiI, por ejemplo, al examinar varios reglamentos de policía y orden urbano, el autor hace notar que a fines del siglo XIX la ciudad de Aguascalientes era sucia y peligrosa; que las calles no tenían banquetas; que por las acequias no corría agua limpia y cristalina, sino ríos de lodo pestilente; que la iluminación de plazas y jardines era insuficiente; que las fachadas de las casas ofrecían en su mayor parte un aspecto lamentable; que la gente tenía la arraigada costumbre de satisfacer sus necesidades fisiológicas en las esquinas; que el calzón de manta que usaban los pobres ofendía el pudor de las llamadas "clases educadas"; 
que auténticas legiones de pordioseros obstruían el acceso a los templos; que los bailes y fandangos populares terminaban muchas veces en bacanales fuera de control; que las bodas llegaron a ser en Jesús María el pretexto para que los indios se amotinaran; que muchas veces las pastorelas no eran funciones piadosas, sino el pretexto de grandes borracheras; que durante la procesión del viernes santo rateros de toda catadura y "léperos enamorados" hacían de las suyas; que los perros callejeros nada sabían de moral pública y se apareaban en los andadores del Parián; que en todos lados se amontonaban los desperdicios; que poco o nada se logró contra el inveterado hábito de beber colonchi, mezcal, pulque, tejuino. chinguirito y otros muchos brebajes, y que en tiempos de lluvias la ciudad parecía una nueva Venecia, sólo que sin románticos paseos en góndola.

En suma, dice el autor, por un lado tenemos al gobierno, tratando infructuosamente de desarraigar costumbres populares, de reformar a los individuos y de reglamentar mediante bandos "todos los aspectos de la vida diaria", y por el otro a una sociedad "que se niega a abandonar sus formas y patrones de vida, resistiendo sorda y tenazmente" (p. 235). Con buen humor e irreverencia, un semanario de oposición resumió las cosas diciendo que la oscuridad y la suciedad que reinaban en Termápolis sólo eran comparables a la tenebrosa ignorancia que había "en el cerebro de nuestros ediles".

Es evidente que esta descripción despiadada pero exacta contradice la imagen romántica pero falsa que se ha ofrecido muchas veces del Aguascalientes decimonónico, sobre todo en la época porfiriana, uno de cuyos ejemplos mejor conocidos son los relatos autobiográficos de Arturo Pani, en los que aparece una ciudad de calles limpias y bien empedradas, una urbe que ve transcurrir los días "en un ambiente de armónica quietud en el que nada disuena". Para contrarrestar los efectos que tienen ciertamente estas descripciones funtasiosas en la mente de los lectores, incluidos los historiadores, Javier Delgado nos ofrece unas buenas dosis de esas ásperas pero muy sanas y hasta divertidas pócimas que son el realismo y la exactitud históricas.

También debe abonarse a la cuenta de los aciertos del libro el aprovechamiento inteligente y sistemático de los fondos documentales del Archivo Municipal de Aguascalientes, los cuales, si bien no eran del todo 
desconocidos, no habían sido tampoco objeto de estudio concienzudo. La consulta de esos papeles permite al autor enriquecer el conocimiento y la comprensión de la época, y en particular revalorar el papel del ayuntamiento. Se había asumido que con respecto al gobernador el ayuntamiento había jugado siempre un rol menor, si no es que de franca subordinación, pero lo que leemos en este libro desmiente esa visión, pues el cabildo fue siempre más aguerrido, combativo y tenaz de lo que habíamos imaginado. En muchos momentos, incluso, fue el equivalente de una verdadera fuerza política de oposición, contra la que el gobernador y sus hombres, empezando por el jefe político del partido de la capital, tuvieron que emplearse a fondo. Como dice el autor, es necesario

matizar la tan difundida idea de que los ayuntamientos, limitados absolutamente por la influencia e importancia del jefe político, estuvieron reducidos a la nulidad política durante buena parte del siglo XIX; los testimonios y casos estudiados, al menos para el estado de Aguascalientes, apuntan en otra dirección y sirven para demostrar que los cabildos, en la práctica política y a pesar de las restricciones legales, no siempre estuvieron sujetos a la voluntad del gobernador y del jefe político. (pp. 281-282)
Estos argumentos echan por la borda esa otra idea romántica e ingenua que tenemos de nuestra historia política e institucional, según la cual Aguascalientes es la "tierra de la gente buena". Aquí no hay pleitos ni divisiones, pues los hombres del poder están al parecer dotados de la extraña virtud de sacrificarlo todo en aras de la "unidad política" del estado. Si eso es evidentemente falso hoy en día, también lo fue hace más de cien años, cuando el gobernador Rodrigo Rincón trataba en balde de someter a los levantiscos regidores y de imponer como presidente de la corporación a uno de sus incondicionales (pp. 9399). En determinado momento, Rincón decidió jugarse el todo por el todo y destituyó a todos los miembros del ayuntamiento, pero la respuesta le vino desde Tuxtepec, pues el triunfo de la revolución porfirista implicó, entre otras cosas, una reorganización política a fondo del estado. De hecho, el que tuvo que abandonar el cargo fue el gobernador Rincón, al mismo tiempo que muchos de los regidores y diputados que se le opusieron recuperaban sus cargos e incluso mejoraban su posición. No deja de ser aleccionador el hecho de que esta revaloración del papel de ayuntamiento sea en buena medida el re- 
sultado del rescate y el estudio de sus propios fondos documentales.

\section{ESPECIFICIDADES DE LA HISTORIA} REGIONAL

Debe mencionarse también entre los méritos del libro la forma amplia, inteligente y crítica en la que se asume el análisis del acontecer regional. En muchos libros se iguala lo regional a lo local, olvidando por completo la perspectiva nacional. Este es un grave error, pues ninguna región o localidad mantiene un pulso histórico independiente o ajeno a lo que pasa más allá de sus fronteras. Hacemos historia regional, pero pocas veces nos tomamos la molestia de definir en forma crítica el concepto de región o de caracterizar la región que trabajamos. Es evidente que el acontecer nacional condiciona e influye de muchas maneras en la historia local y que ésta, por lo mismo, no puede reconstruirse en forma adecuada sin considerar el contexto general.

Esta idea, sin embargo, conduce en ocasiones a otro grave error de perspectiva, según el cual el acontecer local no es sino la repetición, con ligeras variantes, de lo que sucede a nivel central. Las historias locales serían, así, pequeñas puestas en es- cena de ese libreto escrito por los grandes políticos de la ciudad de México. De esta manera, si se estudia el Porfiriato, se dedica uno en vano a buscar pequeños dictadores, o si se estudia la época de la Reforma lo que debe encontrarse es la versión local de esos "gigantes" que según Daniel Cosío Villegas integraron el Congreso Constituyente de 1857.

Evitando la doble tentación del localismo miope y los reduccionismos centralistas, Javier Delgado propone una perspectiva regional equilibrada, que le da a lo local su peso específico, sin ignorar la influencia no pocas veces avasallante de lo nacional. La suya es una crónica centrada en acontecimientos de carácter local, que sin embargo se mantiene atenta a lo que pasaba en la ciudad de México, donde tantas cosas se han resuelto siempre, y en otras regiones del país. La visión que nos propone de la República Restaurada y el Porfiriato no es, en consecuencia, un relato colorido de extravíos locales, sino la historia de una región en la que los problemas nacionales se viven y resuelven de una manera específica.

Esta forma de entender el quehacer historiográfico regional le permite al autor entender las especificidades locales que se advierten en la 
evolución de las jefaturas locales y proponer al mismo tiempo una útil y sana comparación con lo que sucedió en otras entidades. En Coahuila y Jalisco, por ejemplo, se adoptan a fines del XIX medidas que en Aguascalientes se habían tomado desde principios del Porfiriato, tendientes a reafirmar "la capacidad de las jefaturas para subordinar y controlar a los ayuntamientos". (p. 73)

\section{UNA OBSERVACIÓN CRÍTICA}

La segunda parte del libro, aunque interesante y rica en información, me parece menos bien lograda e integrada que la primera. Es evidente que el autor hace un esfuerzo para mantener el hilo de su argumentación, pero también lo es que algunos capítulos, más que demostraciones de las tesis principales, parecen digresiones un tanto alejadas del propósito central de la obra, o aplicaciones forzadas de la teoría. El capítulo IX, por ejemplo, propone un recuento aproximado de las andanzas de los bandidos durante la época de la República Restaurada y los primeros años del Porfiriato, que ciertamente reviste interés, pero no es del todo clara la forma en la que ese recuento demuestra o ilustra las tesis sobre el mante- nimiento del orden y el papel que en ello jugaban los jefes políticos. En el capítulo XI se atribuye a la división de la ciudad en comisarías el propósito de inmovilizar a la población y regular sus movimientos, pero el planteamiento y la demostración no resultan convincentes. A ratos, la argumentación se expone de tal manera que el lector puede quedarse con la impresión de que los integrantes del cabildo, y sobre todo los redactores de los reglamentos, fueron algo así como auténticos precursores involuntarios de las teorías de Foucault sobre el control social.

\section{LOS JEFES POLÍTICOS COMO}

INTERMEDIARIOS DEL NUEVO ORDEN SOCIAL

En el último capítulo se evalúa la contribución de los jefes políticos a la construcción del nuevo orden social soñado por los liberales. El gobierno pretendió "reducir a la sociedad a un campo de vigilancia similar a un tablero de ajedrez, cuidadosamente dividido en compartimientos estancos, cada uno perfectamente iluminado y ocupado por ciudadanos normalizados y homogeneizados", pero la terca realidad impuso sus fueros, de tal manera que en el panóptico liberal pueden observarse un montón 
de "hoyos y grietas", señales evidentes de que "el objetivo de la reforma social nunca pudo alcanzarse por completo". En el contexto de este desfase es interesante la evaluación que se propone del papel de jefe político:

El resultado de esta tensión convierte al jefe político no ya en el gran carcelero y reformador de la sociedad, sino en un intermediario entre el gobierno y los diferentes grupos sociales, [alguien] que en cierta manera se encarga de establecer un equilibrio entre lo que deseaba la élite del gobierno -la reforma social instrumentada desde arriba y llevada a cabo de manera policiaca y disciplinariay las formas de comportamiento populares. Fomentando la corrupción, otorgando favores que fortalecían las relaciones de clientelismo y, en general, negociando [al margen de la ley] a través de cuerpos policiacos ineficientes, la institución de la jefatura política pasa de ser una instancia reformadora a otra intermediadora que trata de encontrar espacios de convivencia mutuamente benéficos con la sociedad.

Pienso que estas palabras constituyen un buen resumen del libro. Creo también que el trabajo de Javier Del- gado enriquece en forma concreta y tangible el conocimiento que tenemos de la historia regional. Tratándose de un historiador tan joven y empeñoso, parece evidente que se trata apenas de la primera de una serie larga de contribuciones.

Se dice que en Aguascalientes estamos "orgullosos de nuestro pasado" y se sugiere que, de alguna manera, ese orgullo nos ayuda a encarar las tareas del presente y a prever las del porvenir. No soy tan optimista. El paso del tiempo y la frecuentación de los libros de historia me han convertido, en forma hasta cierto punto irónica, en un historiador desencantado, que mira con escepticismo la euforia de quienes proponen una imagen romántica e idealizada de nuestro pasado. Sin embargo, estoy absolutamente convencido de que un libro como el que hoy presentamos, a pesar o precisamente porque contradice esa idea romántica, nos puede ayudar a los aguascalentenses a nutrir nuestro orgullo provinciano de buena cultura histórica. 